\title{
Medical and Surgical Treatment of First Trimester Miscarriage, A Randomized Controlled Trial
}

Amr Ahmed Abdelrhman, Tarek Abd Elhamid El Behiedy, Aya El Sayed Mostafa Mohamed*, Mohamed Ramadan Ali

Department of Obstetrics and Gynecology, Faculty of Medicine, Zagazig University, Egypt

*Corresponding Author: Aya El Sayed Mostafa Mohamed, Mobil: 01013321544, E-mail: ayaatty8@gmail.com

\begin{abstract}
Background: Abortion is a common complication of early pregnancy that can have both medical and psychological consequences. Complications following spontaneous or induced abortion are a major cause of maternal morbidity. Objective: To better management and improving outcome of first trimestric miscarriage.

Patients and Methods: A randomized clinical trial study was conducted at obstetric outpatient clinic, Gynecology and Obstetrics Department, Zagazig University during the period from May 2019 until June 2021. The study included 52 women suffering from abortion who were randomized to receive either medical treatment: $800 \mu \mathrm{g}$ misoprostol prescribed as $400 \mathrm{mg}$ orally and $400 \mathrm{mg}$ vaginally or surgical treatment: evacuation with dilatation and curettage. All patients were followed up with a transvaginal ultrasonography (U/S). Results: The mean of endometrial thickness after treatment was $12.5 \pm 2.65 \mathrm{~mm}$ and $8.3 \pm 1.97 \mathrm{~mm}$ in misoprostol and surgical evacuation group respectively, the difference between both groups was statistically significant $(\mathrm{p}<0.05)$. Failed treatment was in $8(30.7 \%)$ patients in misoprostol group and in $2(7.7 \%)$ patients in surgical evacuation group. The difference in failure rate between both groups was significant statistically. Conclusions: A single dose of $800 \mu \mathrm{g}$ misoprostol given as outpatient treatment may be used as first line in management of incomplete abortion.
\end{abstract}

Keywords: Abortion, First Trimestric Miscarriage, Misoprostol.

\section{INTRODUCTION}

Abortion is the most common complication of early pregnancy, and remains an important clinical problem. Approximately $20 \%$ of women attending early pregnancy units suffer an abortion. Most women will present with history of vaginal bleeding, abdominal pain or both, which are traditionally associated with abortion. However significant proportion of women will be asymptomatic. Knowledge of the pathophysiology of this condition is limited and therefore therapeutic regimens are based on few data ${ }^{(1)}$.

The overall early pregnancy loss rate is thought to be nearly $50 \%$. At least $15 \%$ of fertilized ova are lost before implantation ${ }^{(2)}$ and $20-25 \%$ of pregnancies end before they can be clinically detected ${ }^{(3)}$, leading to an incidence of spontaneous abortion of some 12-19\% among clinically recognized pregnancies ${ }^{(4)}$.

The management of abortion has changed little and conventional surgical evacuation of the uterus has been recommended when there are retained products of conception. However, the technique carries a small but a real risk of morbidity and mortality ${ }^{(5)}$.

The method involves the combined use of the antiprogesterone, mifepristone, and the prostaglandin E1 analogue, misoprostol has been shown to result in lower costs per patient, compared with surgical treatment ${ }^{(\mathbf{6})}$.

Misoprostol, a prostaglandin analogue, binds to myometrial cells to cause strong myometrial contractions leading to expulsion of tissue. This agent also causes cervical ripening with softening and dilation of the cervix. Misoprostol binds to and stimulates prostaglandin EP2 receptors, prostaglandin EP3 receptor and prostaglandin EP4 receptor but not prostaglandin EP1 receptor and therefore is expected to have a more restricted range of physiological and potentially toxic actions than prostaglandin E2 or other analogs, which activate all four prostaglandin receptors $^{(7)}$.

The drug, misoprostol, has been used to reduce the risk of stomach ulcers that occur in people who take certain pain relievers. Misoprostol is now more commonly used to stimulate contractions of the uterus. In recent years, physicians have begun prescribing misoprostol in place of surgery to women who have experienced an abortion ${ }^{(8)}$.

In recent years, the medical management of abortion, which can achieve complete uterine evacuation in $95 \%$ of early abortions, has been developed as a realistic alternative to surgical evacuation ${ }^{(9)}$. The aim of this study was better management and improving outcome of first trimestric miscarriage.

\section{PATIENTS AND METHODS}

52 patients were recruited for this study from obstetric outpatient clinic. They were suffering from first trimestric abortion.

\section{Ethical consent:}

An approval of the study was obtained from Zagazig University Academic and Ethical Committee. Every patient signed an informed written consent for acceptance of sharing in the study. This work has was out in accordance with the Code of Ethics of the World Medical Association (Declaration of Helsinki) for studies involving humans.

This article is an open access article distributed under the terms and conditions of the Creative

Commons Attribution (CC BY-SA) license (http://creativecommons.org/licenses/bv/4.0/) 
Inclusion Criteria: Pregnant women at $1^{\text {st }}$ trimester. Age from 18 to 35 years. Patients confirmed to be pregnant by serum B-hCG and presenting with incomplete or missed first trimestric miscarriage. Complaining of: Mild or moderate vaginal bleeding. Mild to moderate abdominal pain. TVS shows no fetal cardiac pulsation (activity) and products of conception. Exclusion Criteria: Patients with severe vaginal bleeding. Patient with severe intolerable pain. Patients who were hemodynamically unstable. Patients with signs of sepsis. Patients with any contraindication to misoprostol: as bronchial asthma. Patients with threatened abortion. Confirmed or suspected ectopic pregnancy. Allergy to prostaglandin in general, or specific to misoprostol. Presence of intrauterine device (IUD). Induced abortion and therapeutic abortion.

All patients were subjected to detailed medical history, thorough clinical examination; the patients were subjected to careful general, abdominal and local examinations. General examination including; vital signs, cardiac and chest examination, head and neck examination, lower limb examination and lastly abdominal examination. Local examination: including inspection of external genitalia. Pervaginal examination and bimanual examination to detect size of uterus, its position, mobility and any cervical mass or adnexal masses examination of cervical dilatation and vaginal bleeding. All patients were followed up with a transvaginal ultrasonography for detection of uterine size, uterine cavity and presence of products of conception.

\section{Method of randomization:}

Computer generated random allocation; individuals were randomized to either medical treatment: $800 \mu \mathrm{g}$ misoprostol prescribed as $400 \mathrm{mg}$ orally and $400 \mathrm{mg}$ vaginally or surgical treatment: evacuation and curettage. Consecutively numbered sealed opaque envelops were used to conceal the group assignment before randomization. These envelops were opened after enrolment of the patient to the study.

Group 1 (medical group): This group included 26 patients and they were medically treated at outpatient,
$800 \mu \mathrm{g}$ misoprostol (misotac, Sigma, Egypt) (4 tablets) was prescribed as $400 \mu \mathrm{g}$ orally (2 tablets) and $400 \mu \mathrm{g}$ vaginally ( 2 tablets) and to be repeated after 24 hours (If not responding it was turned into surgical evacuation).

Group 2 (Surgical group): This group included 26 patients who underwent dilatation and curettage (D\&E).

All patients received general anesthesia, patient was put in lithotomy position after disinfection, evacuation of urinary bladder. A posterior vaginal wall retractor was inserted in the vagina. Cervix was grasped with a tenaculum. Cervical dilatation was done if needed up to $7 \mathrm{~mm}$ using successively larger Hegar's dilators. A blunt curette was inserted through the cervix to the uterine cavity then removing uterine contents and curettage of the lining was done until gritty sensation was felt. Ecbolics in the form of IV syntocinon was given in the event of severe vaginal bleeding. All patients were asked to return immediately if severe vaginal bleeding occurs, otherwise to check after one week for follow up with transvaginal $\mathrm{U} / \mathrm{S}$.

Treatment was considered successful if: No persistent vaginal bleeding and transvaginal ultrasound showed no products of conception.

\section{Statistical analysis}

The collected data were coded, processed and analyzed using the SPSS (Statistical Package for the Social Sciences) version 22 for Windows $®$ (IBM SPSS Inc, Chicago, IL, USA). Data were tested for normal distribution using the Shapiro Wilk test. Qualitative data were represented as frequencies and relative percentages. Chi square test $(\chi 2)$ was used to calculate difference between two or more groups of qualitative variables. Quantitative data were expressed as mean \pm SD (Standard deviation). Independent samples t-test was used to compare between two independent groups of normally distributed variables (parametric data). $\mathrm{P}$ value $<0.05$ was considered significant.

\section{RESULTS}

Table 1 showed the descriptive data of the studied group.

Table (1): Descriptive data of the studied groups

\begin{tabular}{|c|c|c|c||}
\hline & $\begin{array}{c}\text { Misoprostol group } \\
\mathbf{N = 2 6}\end{array}$ & $\begin{array}{c}\text { Surgical evacuation group } \\
\mathbf{N = 2 6}\end{array}$ & p value \\
\hline Age (years) & $27.3 \pm 5.21$ & $26.7 \pm 5.10$ & 0.677 \\
\hline Gestational age (weeks) & $9.8 \pm 1.65$ & $8.5 \pm 1.79$ & 0.009 \\
\hline Parity & $2.6 \pm 1.28$ & $2.9 \pm 1.29$ & 0.37 \\
\hline $\begin{array}{c}\text { History of previous } \\
\text { abortions }\end{array}$ & $0.67 \pm 0.844$ & $0.60 \pm 0.968$ & 0.777 \\
\hline BMI $\left(\mathrm{kg} / \mathrm{m}^{2}\right)$ & $26.10 \pm 2.664$ & $26.50 \pm 1.676$ & 0.52 \\
\hline
\end{tabular}

Table 2 showed that as regard the mean of systolic and diastolic blood pressure and of pulse rate, there was statistically significant difference between before and after treatment in both groups, while for temperature, the difference was significant only in misoprostol group. 
Table (2): Vital signs among the study groups

\begin{tabular}{|c|c|c|c|c|}
\hline Vital Data & & Before treatment & After treatment & p value \\
\hline \multicolumn{5}{|c|}{ Misoprostol group $\mathrm{N}=26$} \\
\hline \multirow{2}{*}{ Blood pressure } & Systolic & $120.2 \pm 5.58$ & $111.17 \pm 4.33$ & $<0.05$ \\
\hline & diastolic & $76.7 \pm 4.91$ & $72.23 \pm 4.88$ & $<0.05$ \\
\hline \multicolumn{2}{|c|}{ Pulse } & $81 \pm 3.58$ & $90.30 \pm 2.89$ & $<0.015$ \\
\hline \multicolumn{2}{|c|}{ Temperature } & $36.1 \pm 0.08$ & $39.276 \pm 1.17$ & $<0.005$ \\
\hline \multicolumn{5}{|c|}{ Surgical evacuation group $N=26$} \\
\hline \multirow{2}{*}{ blood pressure } & systolic & $118.7 \pm 6.79$ & $102.1 \pm 5.22$ & $<0.001$ \\
\hline & diastolic & $75.8 \pm 4.86$ & $70.50 \pm 4.66$ & $<0.05$ \\
\hline \multicolumn{2}{|c|}{ Pulse } & $82.5 \pm 4.04$ & $97.40 \pm 4.77$ & $<0.009$ \\
\hline \multicolumn{2}{|c|}{ Temperature } & $36.9 \pm 0.08$ & $37.100 \pm 0.07$ & 0.127 \\
\hline
\end{tabular}

Table 3 showed that regarding severity of vaginal bleeding, the difference between both groups was significant statistically.

Table (3): Side effects among the studied groups

\begin{tabular}{|c|c|c|c|c|}
\hline & & $\begin{array}{c}\text { Misoprostol group } \\
\mathrm{N}=26\end{array}$ & $\begin{array}{c}\text { Surgical } \\
\text { evacuation group } \\
\mathrm{N}=26\end{array}$ & P Value \\
\hline \multicolumn{2}{|l|}{ Vomiting, diarrhea } & $14(53.8)$ & $8(30.7)$ & 0.092 \\
\hline \multicolumn{2}{|l|}{ Fever } & $17(65.4)$ & $2(7.7)$ & $<0.0001$ \\
\hline \multirow[t]{2}{*}{ Severity of vaginal bleeding } & Mild & $14(53.8)$ & $20(76.9)$ & \multirow[t]{2}{*}{0.080} \\
\hline & moderate & $12(46.1)$ & $6(23.07)$ & \\
\hline \multicolumn{2}{|l|}{ Prolonged bleeding $>3$ days } & $20(76.9)$ & $4(15.3)$ & $<0.0001$ \\
\hline \multicolumn{2}{|l|}{ Infection } & $1(3.8)$ & $2(7.7)$ & 0.552 \\
\hline
\end{tabular}

Table 4 showed that regarding abdominal pain the difference was significant statistically between the 2 groups.

Table (4): Abdominal pain among the studied groups

\begin{tabular}{|c|c|c|c|}
\hline & Misoprostol group $(\mathrm{N}=26)$ & Surgical evacuation group $(\mathrm{N}=26)$ & p value \\
\hline Mild & $2(7.7)$ & $16(61.5)$ & \multirow{2}{*}{$\mathrm{P}<0.0001$} \\
\hline Moderate & $24(92.3)$ & $10(38.5)$ & \\
\hline
\end{tabular}

This study showed that the difference between both groups was statistically significant as regard endometrial thickness (Table 5).

Table (5): Comparison between the studied groups as regards endometrial thickness after treatment

\begin{tabular}{|c|c|c|}
\hline $\begin{array}{c}\text { Misoprostol group } \\
\mathbf{N}=\mathbf{2 6}\end{array}$ & $\begin{array}{c}\text { Surgical evacuation group } \\
\mathbf{N}=\mathbf{2 6}\end{array}$ & $\mathbf{p}$ value \\
\hline $12.5 \pm 2.65$ & $8.3 \pm 1.97$ & $\mathrm{P}<0.0001$ \\
\hline
\end{tabular}

Table 6 showed the general differences between the studied groups

Table (6): General differences between the studied groups

\begin{tabular}{|c|c|c||}
\hline & $\begin{array}{c}\text { Misoprostol group } \\
\mathbf{N = 2 6}\end{array}$ & $\begin{array}{c}\text { Surgical evacuation group } \\
\mathbf{N = 2 6}\end{array}$ \\
\hline Using invasive procedures & Avoids invasive procedures & Involves invasive procedures \\
\hline Anesthesia & Avoids anesthesia & Needs anesthesia \\
\hline Visits & Requires two or more visits & Requires usually one visit \\
\hline Time to complete & Days to week to complete & Complete in a predictable time \\
\hline $\begin{array}{c}\text { Requirement of follow up } \\
\text { Patients satisfaction and } \\
\text { anxiety level }\end{array}$ & $\begin{array}{c}\text { Less satisfied (76\%) and more } \\
\text { anxiety }\end{array}$ & More satisfied (94\%) and less anxiety \\
\hline
\end{tabular}




\section{DISCUSSION}

In our study the difference in the mean of age, gestational age, parity, BMI and history of previous abortions was non-significant between misoprostol and surgical group.

As regards vital data comparing before and after treatment in both groups, there was a drop in blood pressure in both groups before and after treatment and this drop was highly significant in surgical group.

By comparing pulse rate in both groups before and after treatment, there was increase in pulse rate in both groups but it was more significant in surgical group. As well by comparing temperature before and after treatment we found high significant increase in temperature in misoprostol group, but there was no significant difference in temperature in surgical group.

This was in consistence with Behnamfar et al. (10) in their study, which included 133 patients experiencing missed abortion or blighted ovum, with a gestational age less than 12 weeks, the patients received $800 \mathrm{mcg}$ of misoprostol vaginally at the hospital. It was reported that the success rate after using vaginal misoprostol was $92.4 \%$ with minimal effect on vital signs and physical wellbeing. In a randomized controlled trial which included 40 women with incomplete or inevitable abortion, and randomized to surgical, medical or expectant care, Shelley et al. ${ }^{(11)}$ reported less affection of women pulse, blood pressure and respiratory rate with medical and expectant care than with surgical procedures .

As regards presenting symptoms and complications, a significant difference was found between the studied groups in severity of vaginal bleeding, mild bleeding in $14(53.8 \%)$ and in $20(76.9 \%)$ patients in misoprostol group and in surgical group respectively, while moderate bleeding occurred in 12 (46.1\%) and $6(23.07 \%)$ patients in misoprostol group and in surgical group respectively .

Also by comparing duration of bleeding it was > 3 days in 20 (76.9\%) women of misoprostol group and $4(15.3 \%)$ in surgical evacuation group, and the difference was highly significant. A significant difference also was found between groups by comparing gastrointestinal symptoms such as vomiting and diarrhea that was more frequent with misoprostol group. A similar significant difference was found in fever which was much more frequent with using misoprostol. In the other hand infection was more frequent with surgical group and the difference was also significant.

As regard abdominal pain there was moderate pain in 24 and 10 patients in misoprostol group and in surgical group respectively which indicate higher pain score with misoprostol group.

In line with our findings, in a randomized controlled trial, patients in the medical arm had a longer duration of bleeding and a greater need for analgesia. There were no differences in hemoglobin levels, white blood cell count, adverse effects, pain score, and satisfaction with treatment at the follow-up visit. However, more women who received the medical treatment would recommend it or choose it in the future ${ }^{(12)}$.

This was also in line with another study of Patua et $\boldsymbol{a l} .^{(13)}$, which is a randomized controlled trial to evaluate the efficacy and safety of the medical method in the management of first trimester spontaneous onset incomplete abortion, by using misoprostol vaginal tablets, in comparison to surgical evacuation, with an intention of completing the procedure within 24 hours. When analysed after 24 hours of treatment allocation, the efficacy of misoprostol was $91.3 \%$, and the efficacy of the surgical method was $96 \%$, with the statistical difference being insignificant. Procedure-related blood loss and pain perception between the two groups were statistically insignificant. However, the incidence of fever in the misoprostol group statistically appeared higher.

In this study, the mean of endometrial thickness after treatment was $12.5 \pm 2.65 \mathrm{~mm}$ and $8.3 \pm 1.97 \mathrm{~mm}$ in misoprostol and surgical group respectively, the difference between both groups was statistically significant. This was in line with Davar et al. ${ }^{(\mathbf{1 4})}$ who studied dilatation and curettage effect on the endometrial thickness and found that dilatation and curettage has a significant effect on the endometrial thinning.

Also in randomized controlled trial to study ultrasonographic endometrial thickness after medical and surgical management of early pregnancy failure the mean endometrial thickness 14 days after treatment was $9.0 \mathrm{~mm}$ for the misoprostol group and $6.9 \mathrm{~mm}$ for the D\&C group, (difference $2.1 \mathrm{~mm}, 95 \%$ confidence interval [CI] 1.0-3.2). After the ultrasonograms 2 and 14 days after misoprostol, 13 (3.8\%) and 12 (3.2\%) women, respectively, subsequently underwent D\&C. Women requiring D\&C after successful expulsion had significantly greater endometrial thickness than those who did not at 2 days (mean difference $5.2 \mathrm{~mm}, 95 \%$ CI 1.6-8.8) and 14 days (mean difference $5.5 \mathrm{~mm}, 95 \% \mathrm{CI}$ 2.3-8.8) after misoprostol. However, endometrial thickness was a poor predictor of subsequent D\&C. The areas under the receiver operating characteristic curves for endometrial thickness at 2 and 14 days were 0.71 and 0.73 , respectively. Regardless of cutoff values used for predicting subsequent $\mathrm{D} \& \mathrm{C}$, endometrial thickness had a positive predictive value of $40 \%$ or less ${ }^{(15)}$.

In our study there was a general differences between two groups such as using invasive procedures and need of anesthesia that we avoid in misoprostol group but needed for surgical group. But as regard time to complete, need for follow up and number of visits, it took much more time to be completed in misoprostol group. It also needed more visits and more follow up. Patients satisfaction was more in surgical group and anxiety level was higher in misoprostol group. 
This was in line with a randomized controlled trial of Niinimäki et al. ${ }^{(15)}$, which compared the efficacy of the medical treatment to surgical uterine evacuation and patient satisfaction in each group. The success rate was equal (100\% in surgical and $90 \%$ in medical group). More infections were diagnosed in the surgical group. Surgically treated patients were more satisfied with the treatment (100\% vs $88 \%)$. Medical treatment was considered more painful and fewer patients ( $70 \%$ vs $91 \%$ ) would choose the medical method in the future.

In this study, failed treatment was in $8(30.7 \%)$ patients in misoprostol group and in $2(7.7 \%)$ patients in surgical evacuation group while success of treatment was in $18(69.3 \%)$ and $24(92.3 \%)$ patients in misoprostol group and surgical evacuation group respectively. The difference in failure rate between both groups was significant statistically. This was in line with a randomized clinical trial by Zhang $\boldsymbol{e t} \boldsymbol{a l} .{ }^{(\mathbf{8})}$ who demonstrated that misoprostol is an acceptable alternative to vacuum aspiration for the management of early pregnancy failure, with success rate of medical management was $84 \%$ compared to the $97 \%$ success of surgical management. This was also consistence with another study, which assessed whether $400 \mathrm{mcg}$ sublingual misoprostol could effectively evacuate the uterus after incomplete abortion. The study included 302 women and it was found that $96.3 \%$ of participants had successful completions using a single dose of 400 mcg misoprostol ${ }^{(16)}$. Similar results were reported in a previous study which used the same regimen ${ }^{(17)}$.

\section{CONCLUSION}

A single dose of $800 \mu \mathrm{g}$ misoprostol given as outpatient treatment may be used as first line in management of incomplete abortion. Further studies are recommended to compare between different doses and different routes as regards efficacy and incidence and tolerability of side effects of misoprostol. Surgical evacuation is an effective, rapid and safe method for management of incomplete abortion.

\section{REFERENCES}

1. Jauniaux E, Farquharson $\mathrm{R}$, Christiansen $\mathrm{O}$ et al. (2006): Evidence-based guidelines for the investigation and medical treatment of recurrent miscarriage. Human Reproduction, 21 (9): 2216-2222.

2. Henderson J, Hwang A, Harper C et al. (2005): Safety of mifepristone abortions in clinical use. Contraception, 72: $175-178$.
3. Hasan R, Baird D, Herring A et al. (2010): Patterns and predictors of vaginal bleeding in the first trimester of pregnancy. Ann Epidemiol., 20 (7): 524-531.

4. Prine L, Macnaughton H (2011): Office management of early pregnancy loss. American Family Physician, 84 (1): 75-82.

5. Rausch M, Lorch S, Chung $K$ et al. (2012): A costeffectiveness analysis of surgical versus medical management of early pregnancy loss. Fertil Steril., 97(2): 355-360.

6. Odeh M, Tendler R, Kais M et al. (2010): Early pregnancy failure: factors affecting successful medical treatment. IMAJ Isr Med Assoc J., 12: 325-8.

7. Moreno-Ruiz N, Borgatta L, Yanow S et al. (2007): Alternatives to mifepristone for early medical abortion. Int J Gynaecol Obstet., 96: 212-218.

8. Zhang J, Gilles J, Barnhart $\mathrm{K}$ et al. (2005): A comparison of medical management with misoprostol and surgical management for early pregnancy failure. $\mathrm{N}$ Engl J Med., 353(8): 761-9.

9. Neilson J, Gyte G, Hickey M et al. (2013): Medical treatments for incomplete miscarriage. Cochrane Database Syst Rev., 28(3): 7223-7228.

10. Behnamfar F, Mahdian M, Rahimi F et al. (2013): Misoprostol Abortion: Ultrasonography versus BetahCG testing for verification of effectiveness. Pak J Med Sci., 29 (6): 1367-1370.

11. Shelley J, Healy D, Grover S (2005): A randomised trial of surgical, medical and expectant management of first trimester spontaneous miscarriage. Aust $\mathrm{N} \mathrm{Z} \mathrm{J}$ Obstet Gynaecol., 45 (2): 122-7.

12. Moodliar S, Bagratee J, Moodley J (2005). Medical vs. surgical evacuation of first-trimester spontaneous abortion. International Journal of Gynecology \& Obstetrics, 91(1): 21-26.

13. Patua B, Dasgupta M, Bhattacharyya S et al. (2013). An approach to evaluate the efficacy of vaginal misoprostol administered for a rapid management of first trimester spontaneous onset incomplete abortion, in comparison to surgical curettage. Archives of Gynecology and Obstetrics, 288(6): 1243-1248.

14. Davar R, Firouzabadi R, Ara K (2013). Dilatation and curettage effect on the endometrial thickness. Iranian Red Crescent Medical Journal, 15(4): 350-357.

15. Niinimäki M, Jouppila $P$, Martikainen $H$ et al. (2006). A randomized study comparing efficacy and patient satisfaction in medical or surgical treatment of miscarriage. Fertility and Sterility, 86(2): 367-372.

16. Ngoc N, Shochet T, Blum J et al. (2013): Results from a study using misoprostol for management of incomplete abortion in Vietnamese hospitals: implications for task shifting. BMC Pregnancy and Childbirth, 13: 118-123.

17. Shochet T, Diop A, Gaye A et al. (2012): Sublingual misoprostol versus standard surgical care for treatment of incomplete abortion in five sub-Saharan African countries. BMC Pregnancy Childbirth, 12(1): 127-131. 